\title{
Crustal seismology: traditions and styles from a historical perspective
}

\author{
Aitor Anduaga \\ Basque Museum of History of Medicine and Science, University of the Basque Country EHU/UPV, 48940, Leioa, Spain \\ IKERBASQUE, Basque Foundation for Science, Bilbao, Basque Country, Spain
}

Article history: received May 8, 2020; accepted August 23, 2020

\begin{abstract}
It has often been said that geophysics is an umbrella discipline, and that its various and varied fields remained conceptually autonomous even when configured in the mind of a single scientist. However, to what extent were these fields conceptually autonomous? Was there a single accumulation of geophysical knowledge and practices, or rather diverse traditions? Furthermore, what happens when there is a confluence of traditions rather than an independent accumulation of knowledge? Would it make sense then to talk about any conceptual autonomy and compartmentalized fields? This article examines the historical development of a geophysical specialization developed in multinational settings: crustal seismology. Rather than a conglomerate of autonomous fields, the view of geophysics as an intercalated set of inter-disciplinary fields, research schools, programs, and traditions which seem to concur in the same direction, can be applied to a large extent to geophysics of the Earth's crust. The article shows how these elements interacted and were even transferred from one place to another. It concludes with some reflections on the institutional and procedural relations between academic geophysics, physics and geology.
\end{abstract}

Keywords: History of Science; Seismology; Exploration Geophysics; Geophysical Methods; Earth’s Interior.

\section{Introduction}

This article examines the historical development of a geophysical specialization cultivated in multinational settings: crustal seismology. Analysis covers three countries remarkable for their geophysical advances, England, Germany and the United States, in the period from the 1880s to the 1930s. It is important to note that for each of these countries, academic geophysics was institutionalized around contrasting systems of education and research.

Geophysics has long been regarded as an essentially stable discipline and, hence, formed through regular stages on its way from immature to mature status. This general viewpoint has profoundly influenced the historiography of geophysics, which has often tended to regard its various sub-disciplines as watertight compartments being almost independent of one another. This kind of approach also tends to suggest a cumulative picture of geophysical knowledge that informs us very little about how it was gained, processed, transmitted or disseminated. Moreover, the purported firmness and stability of geophysical discipline begs some questions with regard to the autonomy of 


\section{Aitor Anduaga}

its sub-disciplines: autonomous to what extent and as to what? Issues of this kind have seldom been addressed in historical studies of geophysics, which too frequently tend to overlook crucial questions such as the confluence of traditions or the existence of common threads within the supposedly compartmentalized fields.

Recent research, however, has started to undermine this once-unquestioned cannon of stability associated to geophysical discipline. Historian Gregory Good has argued that disciplines are ever-changing frameworks within which different activities are organized. He has shown how geophysics was assembled by a process of extrication and recombination of various specializations such as seismology, meteorology, vulcanology, oceanography, geomagnetism, hydrology and geodesy. He defines geophysics as a framework of consensus on conceptual, methodological and socio-institutional questions in which its development is never teleological [Good, 2000]. Ronald Doel, who has studied the formation of the earth sciences in the twentieth century, has shown how military funding for geophysics after 1945 helped to such a formation [Doel, 1997].

The existence of autonomous and watertight sub-disciplines in geophysics should be also viewed as doubtful today. For example, during World War I, Ludger Mintrop suggested using portable seismographs to locate enemy guns [Keppner, 1993]. This idea came into fruition in 1917 when the U.S. Navy developed sound ranging equipments with the help of the Western Electric Company [Owen, 1975]. After the war, John Clarence Karcher devised a new method, reflection seismology, aimed at determining the location of oil-field structures. Interestingly, the bond between electrical engineering and the oil industry would lead to explore the Earth's crust by seismic prospecting techniques [Karcher, 1987; Green, 1979; Anduaga, 2009].

I will argue that crustal geophysics should be viewed as an intercalated set of inter-disciplinary fields, research schools, programs, and traditions, rather than an autonomous branch. Only when one examines all these elements does the purported stability and autonomy of geophysical discipline become diluted. I will furthermore show that these elements interacted with each other and were transferred from one place to another. A set of four geophysics cores - or traditions with long pedigree- will be identified in crustal seismology: the Cambridge mathematicalphysics, the Göttingen mathematical and observational geophysics, the U.S. observatory-based data recording tradition, and the U.S. laboratory-based experimental physics.

Let me finish this introduction with a disclaimer and a few considerations. This article is not intended to offer an exhaustive description of the historical development of the seismological studies on the Earth's crust; this is too large a planet for a single prospecting. However, it suggests that certain traditions did operate in the maturation of crustal seismology which affected the evolution of this sub-discipline. Indeed, if it is possible at all to condense a definite conception of "crustal seismology", this certainly must be as much concerned with scientific, as with social and institutional issues. I say "if it is possible" for two reasons.

First, the blurred limits of what I have called "crustal seismology" or even at times "crustal geophysics" do nothing but reflect the blurred nature of research fields, both in the Western world and everywhere. It is well known, as showed by reference works on the history of this sub-discipline [e.g., Mooney, 2007; Agnew, 2003; Doel, 1998], that the Earth's crust was an undefined concept up to the moment Croatian geophysicist Andrija Mohorovičić found the first seismic evidence for it in 1910. Some decades later, the use of this term became noticeable, albeit never pervasive, in textbooks and research articles. Although it is true that nowadays the term is not used, it is also true that the field of seismology comprises several topics of crustal research such as seismicity, composition, structure, and oil and mineral prospecting, not to mention those related to other fields of geophysics. And second, "crustal seismology" is also a conceptual expression in geographical terms. Unquestionably, there were many other research schools, programs, and countries in the pursuit of crustal knowledge. Outstanding among them is Japan. We have only to recall the contributions to instrumental and theoretical seismology by influential personalities such as Fusakichi Omori, Toshi Shida, Hiroshi Nakano, and Kiyoo Wadati, who, in different times and contexts, helped expose and solve the problems which studies on the Earth's crust would bring. However, the lack of both clearly defined traditions and connections with the cores identified above makes it their inclusion inadvisable.

\section{Cambridge mathematical-physics tradition}

The first core originates in the Cambridge mathematical-physics tradition and became visible in what David Kushner first called the "British school of geophysics" [Kushner, 1990, 1993]. It was shaped by two leaders in Victorian physics-William Hopkins and William Thomson (Lord Kelvin) - whose concerns focused on the field of 


\section{Crustal Seismology: traditions and styles}

mathematical physical geology and the solution of interdisciplinary problems of the earth sciences [Smith, 1985; Brush and Gillmor, 1995]. Although they used a variety of approaches in their investigations, they all showed an important, if not vital, commitment to mathematization, which they applied to three central problems: the Earth's structure and the thickness of its crust, the age of the Earth, and causes of glacial eras.

An early physical approach toward the history and structure of the earth emerged with the figure who held the Plumian Chair of astronomy and experimental philosophy at Cambridge (1883-1912), George Darwin. Charles Darwin's son applied to the various series of investigations undertaken throughout his career a scientific methodology that was at once analytical and numerical-computational. Through this methodology, his applied mathematics and his persistent search for quantitative results, he contributed to the transformation of the physical geology into modern geophysics. Basically, his methodology began with defining the problem and setting its boundary conditions. Next he analyzed the bound problem by introducing two simplifications: first, he treated the physical reality with the best possible mathematical model; and then he undertook the first analysis after reducing the number of parameters. He always tried to give results a physical meaning. If they were not satisfactory, he increased the number of parameters. He repeated all this operation as many times as necessary until achieving an approximation of the real-world situation [Kushner, 1993]. The simplification of problems as analytically and systematically as possible and the ensuing physical interpretation of results formed the basis of the methodology of his successor, Harold Jeffreys - the father of twentieth-century British geophysics.

Historians have unraveled many institutional and personal idiosyncrasies that gave the development of geophysics in Britain its peculiar character. The relatively amateur nature of scientific activities in nineteenthcentury Britain delayed the consolidation of geophysics into a university discipline. In fact, it was not until 1931 that the first University reader in Geophysics (Jeffreys) was appointed [Cook 1990]. This contrasts markedly with the early institutionalization of geophysics in Germany, favored by the university-based tradition of professional science. An important influence was also exerted by the close relationship between geophysics and astronomy, and by the perennial practice of viewing the field of terrestrial physics from the astronomical perspective. The long shadow of Newtonian physical astronomy in Britain, stronger than in Germany, undoubtedly contributed to the late institutional emancipation of geophysics from astronomy. Likewise, Darwin's personal style guided the pattern of future methodology in the field, and placed emphasis on analysis and quantity rather than on quality; that is, on the applicability of mathematics and the quest for numerical results rather than on qualitative evidence. As a result, British geophysics advanced in the twentieth century but did so in such a way that it had loose ties with geology and strong institutional and filial links with astronomy [Kushner, 1993].

The long-standing dependence of geophysics on astronomy was most frequently viewed as unique to Britain in the twentieth century, and there can be no denying that the argument had substance. Although it never did become a sub-field of astrophysics, as some advocated at the time, the motives for disciplinary dependence had always been overtly institutional. For example, the first geophysical committee organized to foster meetings and discussions among the branches of this field was the responsibility of the Royal Astronomical Society (RAS) in 1919 [Jeffreys, 1936]. The first British journal exclusively devoted to geophysics was the influential Geophysical Supplement (renamed Geophysical Journal in 1958) of the Royal Astronomical Society. The Chair of the leading British authority on geophysics (again, Jeffreys) was the Plumian professorship in astronomy-geophysics only had the rank of reader. There were enough connections, in all the cases, to understand the inclusion of geophysical studies into disciplines such as planetary science. In fact, issues such as tidal friction or large-scale climate change shared both fields [Brush, 1978]. But the effect was clearly and manifestly to provide an approach that gave prevalence to quantitative over qualitative reasoning; whether to promote diffusion and communication (as in the case of the committee and the journal), or to teach fundamentals (as in the case of the Chair).

The continued readiness of most geophysicists to comply with the quantitative conception of the astronomical methodology cannot conceal the fact that Harold Jeffreys marked a turning point for the discipline. Both the nature and the epistemological status of geophysics, especially crustal seismology, underwent a fundamental change [Jeffreys and Jeffreys, 1971-1977]. In the 1910s, this Cambridge mathematician formulated an entirely new theory of induction that was brilliantly addressed in his work Scientific Inference in 1931 [Jeffreys, 1931]. This book was to reinforce the value of induction and probability as tools for analysis, and to refute the thesis of a hypothetical "geophysical style" based on deductive reasoning and quantitative evidence. The reversal is all the more revealing since it came from someone who was not averse to Darwinian analysis. But Jeffreys shed new light by formulating an epistemological program based upon inductive inference and probabilistic analysis. As a part of this program, 
he defined "simplicity" as an epistemological category, and formulated what he called the "simplicity postulate"; i.e., "the simpler the law, the greater is its prior probability" [Jeffreys and Wrinch, 1921]. In the 1920s, Jeffreys devised a new method of seismic analysis and applied both this method and his simplicity postulate to the structure of the Earth's crust. As a methodological procedure, he devised crustal models of layerlike simplicity [Jeffreys, 1926]. Although geological evidence seemed to point in another direction, Jeffreys always preferred epistemological criteria to evidential ones.

By World War II, the Jeffreysian crustal model achieved a dominant position. It had strong advocates such as Cambridge seismologists Robert Stoneley and Keith Edward Bullen; it had inspired other layered crustal models; and its foundations, in particular the primacy of simplicity and the predilection of seismic analysis over geological evidence, were taught as a guiding core principle in geophysics courses and textbooks. Yet, however homogeneous such a dominion may have appeared in the interwar years, it had never been so without the participation of another crustal seismological tradition, as addressed below [Anduaga, 2016]

\section{Göttingen mathematical and observational geophysics}

The second core of crustal seismological tradition is the other main geophysical focus in Europe: Göttingen. From its establishment in 1898, the Institut für Geophysik der Universität Göttingen housed a good number of graduates who specialized in geophysics under the direction of Emil Wiechert [Wiechert, 1906]. Although they were involved in construction of seismographs, their research interests mainly revolved around on observation and the mathematical theory of seismic-wave propagation. They were all uniformly indoctrinated into the practice of seismogram reading and accurate measurement. However, not all were "crustal seismologists" in the sense that such a categorization might indicate. Furthermore, seismology was not their unique dedication (e.g., atmospheric electricity and aurora were as well). Some devoted themselves to analyze the motion of earthquake waves (Wilhelm Schlüter, Harold D. Arnold); others, to the theory of elastic waves (Zoeppritz), or travel-time curves from seismograms (Herglotz); some also turned to localization of epicenters (Geiger), or the structure of the Earth's core (Gutenberg); and among those focusing attention on the crust, some studied surface waves (Gutenberg, Angenheister), while others used artificial sources (Mintrop, Hans Mothes). However, Wiechert imbued them all with his unified conception of mathematical and observational geophysics. The Königsberg seminar method, based on the handling of instruments and analysis of data and errors, as well as on theory and precision measurement, was the model by which all were inspired [Schweitzer 2003; Cremer 2001; Westermann 2011; Kertz, 2002; Olesko, 1991].

Of several respects in which the Göttingen Institute differed from other foci such as Cambridge or California, two are worth mentioning here. First, by its research projects and organization, Göttingen's geophysics experienced a relatively quick differentiation from astronomy, establishing itself motu propio as an autonomous university discipline. However, in suggesting this more than progressive differentiation, I am making a statement that must be clarified; for even if it is true that 1898 was a turning point, it is also true that the character and objectives of geophysics remained subordinate to astronomy in the various decades up to then. Until the end of the nineteenth century, its role had been straightforwardly ancillary: for example, the first pendulums set up at the astronomical observatories of Göttingen and Potsdam had the mission of measuring earth movements caused by the influence of astronomical bodies [Forbes, 1967]; and even as late as 1896, Wiechert developed a model of the Earth's interior, based only on density and astronomical observations [Brush, 1980]. The idea was not as outlandish as it could seem, as shortly after the first seismological evidence of an Earth's core was given by Richard D. Oldham [1906] in Britain. However, from 1898, when the first geophysical institute in the world was established in Göttingen, the context for the geophysical emancipation began to change, at an institutional and conceptual level. All that occurred just at the time in which the plans by Göttingen mathematician Felix Klein for strengthening mathematics, natural sciences, and technology came to fruition through the patronage of several professors and industrialists [Neuenschwander and Burmann, 1994]. The split of the Chair in theoretical astronomy, geodesy, and geomagnetism into two new professorships in 1897 is typical of the way in which the accumulation of professional forces accelerated, rather than slowed, the autonomy of said discipline.

A second distinctive feature of the Göttingen school was its emphasis on "explosion seismology". From the very start, Göttingen program contained the systematic study of non-seismic sources of ground movements. The case of Ludger Mintrop shows how innovative this initiative was [Schleusener, 1956; Kertz, 1991; Cremer, 2001]. A 
professor at the mining school in Bochum and a land surveyor, Mintrop had conducted research involving the measurement of elastic waves induced by mining explosions. But the idea of deliberately using artificial sources to study seismic-wave propagation was a new challenge by the standards of contemporary seismology. Attracted by this singular challenge, Mintrop used small explosions to generate elastic waves just after joining Göttingen in 1907. He also broke new ground by constructing portable seismographs and patenting novel procedures such as his Method for determination of rock structures, a method he patented in 1919 to interpret travel-time curves [Lehmann, 1965]. This privilege was not reserved only for him; another of Wiechert's pupils, Hans Mothes, was the first to measure the thickness of a glacier by applying seismic surveying methods [Mothes, 1927]. These endeavors symbolize innovating techniques which contributed to the expansion of explosion seismology and the seismic prospecting method not only in Germany, but also in the eastern coast of the U.S. in the 1920s [Mintrop, 1947].

It was certainly the perception that Göttingen was taking the lead, which helped seismic prospecting take root in Germany's industry in the early 1920s. The pace was set by the commercial company Seismos-GmbH, created by Mintrop [Mintrop, 1930)], though the marks of a competitive struggle can now be seen. As soon as the company was founded, in 1921, Richard Ambronn, the head of the rival company Erda-GmbH, took legal steps to stop Mintrop's patent from being accepted [Brinckmeier, 1955]. However, Mintrop's commercial successes in the U.S. tipped the balance in his favor. Seismos, which obtained a contract to conduct seismic surveys for Marland Refining Company in 1923, applied its method along the Gulf Coast of Texas. While this first attempt proved fruitless, subsequent surveys conducted for Gulf Production Company led to the first seismic finding of a salt dome, the Orchard dome in the Texan coast, with significant amounts of oil [Lawyer et al., 2001]. Consequently, from the mid-1920s a substantial number of geophysical companies in the U.S. began emulating Seismos and managed to edge ahead of Germany in applying seismic prospecting methods.

The third and final characteristic of the Göttingen school was its interest in global earthquakes. Through teleseismic, or distant, observations, they provided global seismology with the method of studying the Earth's interior. American seismologists, by contrast, maintained their pre-seismographic practice of studying regional or local earthquakes, adopting the pragmatic view of their precursors, geologists, mining engineers, and astronomers. However, global seismology did not originate at Göttingen; they further developed the German tradition initiated by astronomer Ernst von Rebeur-Paschwitz in 1886 in setting up horizontal pendulums in remote places to monitor the Earth's seismicity as globally as possible [Dewey and Byerly, 1969]. Although indirectly sought (as his aim was to measure the deformation of the ground by tides), Rebeur's instrument (the clinometer) also proved to be sensitive to earthquakes, and, therefore, was set at different places for seismic purposes. They also retained Rebeur's idea of collaborating with distant stations and using their data as references for teleseismic observations. Thus, from 1902, when the Apia Geophysical Observatory was established on the Samoan Islands in the Pacific Ocean, such cooperation finally became viable. Several Wiechert seismographs were set up in Samoa, and Göttingen pupils, such as Angenheister and Geiger, spent some time there. In extending their perspectives worldwide and to international cooperation, Göttingen seismologists felt the satisfaction of being able to precisely locate large quakes in the Pacific area, as well as of having global travel-time curves, important to their investigations on the Earth's core and crust [Pyenson, 1985].

Ironically, the Göttingen Institute's globalist view may well have had significant consequences for American seismology in an episode that began with the arrival of Beno Gutenberg at Caltech University in 1930 [Goodstein, 1984]. Until that date, this seismologist of Jewish origin had meritoriously carved out a name for himself in the world of geophysics [Richter, 1962; Knopoff, 1999]. His contributions included the estimate of the radius of the Earth's core in 1914, as well as the identification of its elastic properties. In 1926, Gutenberg alternated between temporary position of professor of geophysics at the University of Frankfurt-on-Main and of manager of the soap factory that he inherited from his father. But he failed to occupy the vacant Chair at Göttingen in geophysics at a time in which the presence of Jews in university professorships was becoming an affair of State. The impossibility of realizing his full capacity at home convinced him to accept the invitation given by the head of Caltech, Robert A. Millikan, to join the Seismological Laboratory [Hough, 2007; Goodstein, 1984; Wood, 1929]. At that time, Caltech's authorities concluded that a "good seismologist" was necessary, if the institute aimed to progress on the study of the earthquakes in California, as the ongoing research lines seemed clearly insufficient. From his new Chair, Gutenberg made an unprecedented effort to shift the focus of attention from local observations to general dynamical patterns. During his first years at Caltech, he examined North American microseisms and analyzed the global distribution of earthquakes. Then, in the late 1930s, Gutenberg and his Caltech colleague Charles Richter (better 


\section{Aitor Anduaga}

known as the inventor of the scale of earthquakes named after him) revised standard time-distance tables to calculate the velocity of seismic waves [Gutenberg and Richter, 1934, 1935, 1936, 1939]. As a result, the centre of scientific research and production in earthquake seismology unmistakably shifted from the once fertile ground of Göttingen to California.

By World War II, Gutenberg's contribution to crustal seismology was, for all intents and purposes, indisputable. He had stimulated research of outstanding quality, introduced artificial blasting (in the purest style of Göttingen) as a tool to study the outer crust, and he had elucidated the structure of the Earth's crust in California with enough precision. Yet, however successful such participation may have appeared in the 1930s, the implementation of Göttingen's modus operandi ran into a brick wall in Berkeley, northern California.

\section{U.S. observatory-based data recording tradition}

There was an observatory-based data recording tradition in the U.S.- which constitutes our third core-that helped governmental bureaus such as the U.S. Geological Survey and the U.S. Coast and Geodetic Survey to foster geophysical research [Yoder, 2004, pp. 1-3]. This third core originated from the tradition of Humboldtian-style terrestrial physics reaching back to the mid-nineteenth century. In most cases, their methods were qualitative rather than quantitative. Utilitarian concerns derived from geological and geodetic surveys aroused a growing interest in earthquake research on a scale unknown up to that time. Part of this emphasis was placed on researching the relations between faults and earthquakes. But the greatest part of it seems to have been placed on performing geodetic, gravimetric, and magnetic surveying in order to construct charts at a time when geodetic surveys and navigation required accurate observations [Good 1991, 1985].

These agencies responded to national needs. Civilian-governmental agencies such as the U.S. Coast and Geodetic Survey had in fact been established in most Western industrialized countries by the early twentieth century; their aims included magnetic studies and surveys of coastlines which were essential for navigation. Likewise, they contributed to the informal training of young geophysicists. However, these were not the only national needs that stimulated the growth of geophysics.

The scale and strength of this tradition can be seen in the cases of the University of California observatories, Berkeley and Lick [Louderback, 1942; Bolt, 1989]. Berkeley, the main seat of the evolution of twentieth-century observational seismology, was a student observatory with a clearly educational orientation. Lick was an important professional astronomical observatory situated on Mount Wilson. While Berkeley was financed by the California legislature to provide practical training to civil engineers, Lick was the fruit of the bequest from a wealthy man [Leuschner, 1904]. However, both shared the same fate in 1887: they were organized under the same plan, equipped with identical instrumentation, and had the honor of being the first seismographic stations with continuous recording set up in North America [Bolt,1985]. Yet it was astronomers, and not geologists, who were to blame for this initiative. The president of the University, astronomer Edward Singleton Holden, promoted their establishment, not so much by their intrinsically seismological interest, but for the need to keep "a register of all earthquake shocks in order to control the positions of the astronomical instruments" [Louderback, 1942]. In any event, the measure had an incentive effect as just one-year latter several instruments were set in California with the objective to have a record of the region's earthquakes.

Lick and Berkeley's establishment enabled the organization of a coordinated network of seismographic stations in northern California and Nevada; the first network of its kind in America. The records of almost a dozen stations established at local astronomical observatories (such as that at Carson City, Nevada), and Holden's work, gathered in his Catalogue of Earthquakes on the Pacific Coast, 1769-1897 [Holden, 1898], all reflected the commitment to astronomy-oriented observational seismology. To a greater or lesser degree, these stations shaped a style of observational practice aimed at finding solutions to the so-called "California problem" of regional earthquakes [Goodstein, 1984].

Interestingly, the great 1906 San Francisco local earthquake galvanized the joint collaboration of geologists and seismologists; up until this point there had been a lack of organization and coordination between sciences in the U.S. [Geschwind, 2001]. Insofar as the causal link between geological faults and the destructive intensity of earthquakes was searched, collaboration was easy and productive. For instance, three days after the event, the governor of California created the State Earthquake Investigation Commission, half of whose members were 


\section{Crustal Seismology: traditions and styles}

geologists [Lawson, 1908-1910]. Eight months later, the Seismological Society of America was established [Byerly, 1964; Geschwind, 2001]. Social and academic demands were high because of the tragedy's magnitude, and this fuelled the collaboration. As a result, global seismology and the structure of the Earth's interior became secondary objectives; the priorities unmistakably lay in the field of local earthquake seismology and its relation to faulting. Hence, at a time when seismology was being mathematized at Göttingen, new steps towards its institutionalization were taken at Berkeley in ways that even nineteenth-century geologists would have found impressive. Among other steps, we can mention the seismological program founded by the Carnegie Institution in 1921, the first seismology classes for undergraduates in 1911, the first graduate course in seismology in 1923, the program for studying local earthquakes in 1916, or the hiring of key figures in this discipline, all within the University's Department of Geology and Mineralogy [Louderback, 1942, Bolt, 1989]

The character of the seismological program at Caltech was shaped by the established values of the observatories in northern California, namely Berkeley and Lick. The main function of these observatories was to find a practical solution to the hazards of California earthquakes [Wood, 1918]. Accordingly, the Carnegie Institution launched a modest program for the investigation of local earthquakes in 1921 [Goodstein, 1984]. As a proof of its commitment to the field approach and to rigorous instrumental standards, the Berkeley school hired Harry Wood, a Harvard graduate in geology and mineralogy, as the program's director, and Charles Richter, a theoretical physicist very experienced in reading and measuring seismograms, and Hugo Benioff, a skilful seismic instrument designer, as assistants. Research activities were initially conducted at the Carnegie Institution of Washington's Seismological Laboratory in Pasadena and in a seismographic network. By 1927, this network also included the central station at Pasadena and four auxiliary stations in southern California [Geschwind, 2001; Gutenberg, 1934].

At Caltech, a research line in particular-seismic instrumentation-passed from a hesitant infancy to a robust adolescence. Caltech housed Wood and John A. Anderson, who in the 1920s devised a ground-breaking torsion beam seismometer which could photographically record the imperceptible motions of local earthquakes. It was in fact the signals from this seismograph on which Richter drew in 1935 to define his magnitude scale for earthquakes [Richter, 1935; Hough, 2007]. But Caltech also housed virtuous Benioff, who in the 1930s designed one of the best sensors for decades, of much higher sensitivity than any so far built, the result of the adaptation of a variable-reluctance transducer to a seismograph. Benioff's sensors were in fact used in the World-Wide Standardized Seismic Network, which operated from the 1960s to the 1980s. In 1932, he applied his transducer to a strain seismograph, which proved to be particularly useful for recording long-period surface waves from distant earthquakes. To the extent that they provided records of free vibrations at many frequencies, Benioff's strainmeters inaugurated a new branch of instrumental seismology [Press, 1978].

It is consistent with my categorization that California represented the confluence of two traditions, which originated in Berkeley and Göttingen. The former was involved in seeking correlations between seismic phenomena and geological faulting - an issue that had attracted the interest of their precursors, the geologists and mining engineers [Wood, 1916]. Berkeley's seismologists devoted little time to interpreting travel-time curves or devising seismological Earth models; rather, their concerns were oriented towards the study of local earthquakes, that is, the possibility of predicting them or the problems they posed for engineers and architects. Their practical and local approach powerfully contrasted with Göttingen seismologists' globalist view. At Berkeley and then at Caltech, Wood headed the mapping of active faults; also the prediction of large earthquakes (according to him, "weak shocks" were "preliminary to failure in faulting, with resulting strong shocks”) [Bolt, 1985]. At Berkeley, Perry Byerly, a graduate in physics and the first person to receive the title Professor of Seismology at the University of California, who obtained a Guggenheim Fellowship in 1928 to conduct research at Cambridge with Jeffreys, developed a graduate research program [Verhoogen, 1985; Anduaga, 2016]. He instructed his doctoral students (a total of 22 in his long career) how to scrutinize a large earthquake, determining travel-times, its location and depth, and the direction of faulting [Bolt, 1979]. For years, Wood and Byerly's shadows was very long. However, since 1930, as Göttingen-trained seismologist Gutenberg initiated a research program of the world's large earthquakes, the influence exerted by Berkeley pupils in American seismology began to wane. Their regional seismology had proven socially beneficial, but somewhat scientifically limited [Byerly, 1958].

Despite the preeminence of these two foci, the variety of institutions and programs involved is one of the most idiosyncratic aspects of the observatory-based data recording tradition. According to the most common list of seismographs in the U.S., compiled by the Seismological Society of America in 1911, the total number of stations was 44-many of them operated by Jesuits (fifteen) and by the Coast and Geodetic Survey (five) - a figure that grew 


\section{Aitor Anduaga}

slightly in the following decades [Heck, 1944, p. 224]. As time went by, the share of commitment extended to academia, and it was the Jesuit Seismological Service that set the pace [Macelwane, 1926]. Founded in 1909 in Cleveland by Frederick L. Odenbach of John Carroll University, it constituted the "first seismological network of continental scale with uniform instrumentation" [Udías, 2000]. But until 1925, when the Service was revitalized by St. Louis University, Jesuits rarely drew upon stations as a vehicle for research. Emphasis was placed on publicity and acclaim rather than analysis and investigation. Jesuits (and also the U.S. CGS) were interested not so much in fomenting research as they were in collecting earthquake records to send to the Central Bureau of the International Seismological Association in Strasbourg within the European seismological program [Geschwind, 1998].

With this tradition in mind, it is enlightening to focus attention on the one case that seems, at least in its initial stages, to vie as an exception: the Jesuit St. Louis University. This case reflects the commercial and industrial dimension that academic seismology held. Broadly speaking, the introduction of the seismological program at St. Louis in 1925 is comparable to that of Caltech in the early 1920s. Its promoter was the Jesuit Father James B. Macelwane who first graduated from St. Louis and later earned his Ph.D. at Berkeley in 1923 [Macelwane, 1923; Byerly and Stauder, 1958]. Two years later he returned to St. Louis as director of the newly created Department of Geophysics [Geschwind, 1998; Barth, 2000]. Behind this return was his goal-presumably suggested or encouraged by his superiors-to revitalize the Jesuit Seismological Association [Udías and Stauder, 2002]. Like Wood at Caltech, Macelwane designed a seismological program for the department. Yet it was a program geared towards graduate studies in earthquake research, and most importantly in applied seismology. Training graduates for academic positions was an objective of the program, but Macelwane's educational goal was to train exploration seismologists. Basically, his strategy was to build up a network of contacts and acquaintances among the many geophysical consultancies and oil companies in the U.S., some of which Macelwane himself had worked for [Byerly and Stauder, 1958]. Then from an academic position of recognized prestige, he would establish the Institute of Geophysical Technology at St. Louis in 1944 in which many men who ended up serving in high posts in the geophysical staff of oil companies would be trained [Barth, 2000].

Some schools of mines and university geology departments-the centers that promoted exploration seismology and applied geophysics in general-form a separate subgroup with limitations and virtualities very similar to those described above. The path was opened by the Colorado School of Mines, which offered the first official course in geophysical prospecting under the direction of Carl A. Heiland in 1927 [Hollister, 1957; Eckley, 2004]. Unlike other schools at the time, Colorado hired professors with industrial curricula, benefiting from the growing consolidation of applied sciences in mining, particularly in geological engineering [Van Tuyl, 1949]. At the same time, other universities such as St. Louis and Houston's Rice Institute benefited from the proliferation of posts directly or indirectly related to industrial geophysics. Here oil companies and geophysical consulting companies led the demand: by the 1920s, the American oil companies employed a wide variety of geophysical methods, including seismic, magnetic, electrical and gravitational ones [Ochs, 1992]. The growth of exploration geophysics was not only parallel to, but also constituent of the expansion of the petroleum industry.

\section{U.S. laboratory-based experimental physics}

The last core has much bearing on the deeply entrenched U.S. tradition of laboratory-based experimental physics. The Carnegie Institution of Washington (CIW) and Harvard University were actively involved in the early investigations into the physics of the Earth's crust. The two institutions benefited from philanthropic donations. The CIW was founded in 1902 thanks to a ten-million dollar donation from the magnate Andrew Carnegie. His fortune was a daughter of industrialization; in the 1880s, Carnegie Steel was the largest manufacturer of pig iron, steel rails, and coke in the world. The Rockefeller Foundation, for its part, facilitated with grants Harvard's vigorous entry into geophysics in the 1930s [Good, 1991]. Such private patronages placed geophysics firmly on the path of experimental physics.

The CIW set the pace. It is significant and wholly in character that the most important research centre, the Geophysical Laboratory (GL), was founded by the CIW early, in 1905 [Yoder, 1994]. The GL soon stood out as the authoritative source of data on the physics-chemical properties of rocks and minerals [Servos, 1984]. To a certain extent, the GL was the result of a boost in geophysical tradition. In the 1870s and 1880s, a group of geologists from the U.S. Geological Survey (Clarence King, George F. Becker, and Carl Barus) were interested in the inner state and 


\section{Crustal Seismology: traditions and styles}

age of the Earth [Burchfield, 1975]. But that was primarily due to the growing prominence of young geologists and petrographers (like Charles R. Van Hise and Joseph P. Iddings), concerned with physical chemistry and the study of the formation of igneous rocks [Servos, 1984]. As a result, the GL promoted experimental studies in petrology and geochemistry rather than geophysics. It was not until after World War II that more attention was given to leading geophysical questions such as the dynamics of crustal deformations or the measurement of physical constants (e.g., the elasticity and thermal conductivity of rocks), which were important for layered crustal models [Yoder, 2004].

The CIW's managers became convinced that the GL's objective should be focused on physics and seismology rather than on a geochemical tradition that had tipped the balance toward questions relating to petrogenesis and metamorphism [Abelson, 1975]. GL director Arthur L. Day played a major role in this regard [Day, 1938]. Moreover, he received the favorable response of his physicist colleagues. For example, Leason H. Adams and Erskine D. Williamson examined the elastic properties of minerals and rocks by conducting tests of the properties of materials under high pressures. By doing so, they delved into the nature and composition of the Earth's crust [Gibson, 1980; Hemley, 2006]. Others retained their petrologic concerns but centered all their efforts on the issue of propagation of elastic waves through rocks (e.g. [Roy W. Goranson, 1928]). Yet all of them settled on experimentation, making the GL a centre of reference for the increasingly exacting demands of earthquake seismologists.

Interestingly, the attitude of Carnegie authorities had beneficial results for American seismology in the new age that dawned with the development of sensitive motion detectors after World War I. In 1916, Wood, in those days a researcher at the Hawaiian Volcano Observatory, wrote a report on the desirability of establishing a network of seismic stations in southern California [Wood, 1916]. It was also during World War I that Wood designed a device capable of registering vibrations (from cannon fire) that resembled those of local earthquakes. Within a few years, Wood designed a piezo-electric seismometer, emulating the Russian Prince Boris B. Galitzin's work [Wood, 1921]; and, once established in Washington, submitted his plan to Arthur Day who passed it on to John Merriam, the CIW's new president [Goodstein, 1984]. Merriam, a Berkeley geologist and paleontologist who left university teaching in 1920, immediately espoused Wood's plan, forming an Advisory Committee on Seismology composed of five geologists and two physicists under Day's direction at the GL. The Committee constituted not only one of the largest cooperative efforts in American science [Abelson, 1975], but it was also the seed that led to the agreement between the CIW and Caltech, which in 1927 created the Seismological Observatory in the foothills of the San Rafael Mountains [Anderson, 1974]. There can be no denying that, with the entry of the CIW into seismology, Caltech promoted investigations on crustal movements of a scope and magnitude beyond anything previously attempted [Goodstein, 1984].

The case of another geophysical committee, Harvard's, is symptomatic of the existence of an ingrained tradition of experimental physics in the U.S. During the period from the 1870s through the 1910s, most of the U.S. physics departments encouraged experimental practice while neglecting mathematical instruction [Servos, 1986]. The most renowned physicists were experimentalists; such was the case with Robert A. Millikan, Albert Abraham Michelson, Henry August Rowland, to mention but a few. Another distinguished experimentalist was Percy W. Bridgman, also known for his operational doctrines of modern physics, who conducted pioneering investigations on the field of high-pressure physics after joining the Jefferson Laboratory at the Harvard physics department [Kemble and Birch, 1970]. His efforts were focused not only on the application of high-pressure techniques to conditions like those found in the Earth's crust, but also on the subsequent finding and scrutiny of new phenomena under such high pressures. In the interwar years, he was the only physicist who was able to reach pressures of thousands of $\mathrm{kg} / \mathrm{cm}^{2}$ (that is, the type of pressures found several kilometers below the Earth's surface) by laboratory techniques [Okamoto, 2004]. His contributions proved to be highly promising for his colleagues as they expanded the experimental horizons of crustal seismology.

Bridgman's intense personality left a deep imprint on the atmosphere in Harvard in the early 1930s, where geophysicists mingled with geologists to promote experimental geophysics in an era when the two disciplines interacted as never before. The Committee for Experimental Geology and Geophysics played a major role in this promotion. With the financial support given by the Rockefeller Foundation [Birch, 1960], they helped inaugurate a modern style of geophysics that would be reflected in the fulfillment of a two-fold venture [Ahrens, 1966]. On the one hand, a seismological station was established under the direction of Don Leet, which specialized in the study of seismic velocities by using quarry blats. As the director of the new station, Leet published several articles on seismic travel-time curves in cooperation with Maurice Ewing, then instructor at Lehigh University [Bullard, 1980]. On the other hand, building upon Bridgman's experience with high pressure physics, a program of physical 


\section{Aitor Anduaga}

measurement was established at Harvard. This program soon yielded fruitful results, such as the studies on elastic properties of rocks by William A. Zisman, and the works on seismic velocities of rocks by Albert F. Birch. All these studies aimed at determining the physical properties of geologically relevant materials, and consequently, at harmonizing geophysics with geology [Birch, 1979].

\section{Some final considerations}

In a short article it is not possible to introduce highly telling nuances; only the salient features of the historical development of crustal seismology could be raised. Four research traditions are present in this text: Cambridge mathematical-physics, Göttingen mathematical and observational geophysics, U.S. observatory-based data recording, and U.S. laboratory-based experimental physics. There are sound historical grounds for arguing that crustal geophysics should be viewed as an intercalated set of inter-disciplinary fields, research schools, programs, and traditions, rather than a conglomerate of autonomous fields. All these geophysics cores seem to concur in certain directions, or at least, interact with each other by transferring programs and human capital from one place to another.

The historical development of crustal seismology also raises some more general considerations. The first consideration concerns the relationship between academic geophysics and physical sciences. In the United States, unlike in England or Germany, the socio-political context greatly affected the implantation of academic geophysics, which encountered serious obstacles at the turn of the century. Earth sciences enjoyed a preeminent status due to having played a decisive role in the great Western surveys of the 1870s. Yet, by 1900 these sciences underwent a loss of status, owing to the lack of political support and the increasing weight of industrialization [Doel, 1997]. It is no small irony that lies behind these obstacles that led to the primacy of physical sciences over the earth sciences in the U.S. On the one hand, departments of physics from American universities received considerable funds and political backing. Moreover, these very departments hosted, with a greater or lesser presence, some physical disciplines related to earth processes-which belonged to geophysics. On the other hand, the disciplines that compose geophysics, such as seismology or meteorology, were only included as research specialities either because they had no political backing, because they were young, or because they had no close links with industrial sectors. This meant that no exclusive institute or centre of geophysics existed in American universities-a strategy that was scientifically disputable and academically inappropriate, if we compare this to the situation of Europe. Notwithstanding all this, the few programs on interwar seismological research had great impact and academic repercussion. The policy of support received in many departments of physics only increased both.

The second consideration concerns the relationship of crustal geophysics with its so-called "borderland science": geology. In historical terms, this relationship was difficult and complex. Although they were bordering sciences, they had differences in methodology, tradition and style. Academic geophysicists often deemed their science as archetypal of precision and of mathematical rigor, as the triumph of quantitative methods over what they judged to be the qualitative and unproductive methods of geologists - a "negative" perception that little helped understanding between the actors involved [Heiland and Wantland, 1940; Keys, 1940]. The geologists thus trained in academia, were reluctant to accept the crustal models of academic geophysicists, and until the 1940s and the late post-war years, then within a new sociopolitical context, we cannot speak of the integration as such of geophysicists into the departments of geology (or vice versa) [Hubbert, 1940].

In American universities, the departmentalization of the domain of science into conventional fields (such as physics, geology, etc.) did not help understanding between the academic communities of geophysicists and geologists. Ironically, many of the problems (or sources of tension) observed in academia were solved by the industrial geophysical community in the interwar years; a variety of factors contributed to this fact: the same objectives, the use of identical prospecting methods, a structure of values and socioeconomic incentives that encouraged scientists to cooperation (not to inbred isolation), and participation in work crews combining geologists' field experience with physicists' experimental insight. In the case of the American oil industry, these features reflected not only the strength of industrial geophysics, but also the anomalous functioning of academic geophysics. The industrial scientific community had specialized journals, societies (made up of both geophysicists and geologists), common workplaces, a hierarchy of common values; it formally had all the elements favorable for rapprochement and coexistence. Hence, understanding between industrial geophysicists and geologists was not 
comparable to that of any homologous academic department. As I showed on another occasion, the industrial geophysical community had a system of values and prospecting methods which were progressively transferred to academia for scientific research. The post-war coexistence between geophysics and geology was impelled from the industrial world to academia - not the other way around [Anduaga, 2016].

The last consideration concerns the laboratory-based experimental physics tradition. During the first decades of the twentieth century, the late nineteenth-century trend toward the proliferation of laboratory-based physical research was consolidated in the U.S. However, the laboratories founded in those years were headed by experienced, skillful, and able, physicists trained in the European style. The careers of Arthur Louis Day and Beno Gutenberg are illustrative in this regard. After working as professor of physics at the Universities of Yale, Day was trained at the Physikalische Technische Reichsanstalt in Berlin [Abelson, 1975]. It was in this place that Day engaged in hightemperature thermometry in 1897 [Yoder, 1994]. Gutenberg, for his part, was imbued with the Göttingen conception of mathematical and observational geophysics being indoctrinated into the procedures of accurate measurement, long before accepting the post of director in Pasadena [Knopoff, 1999]. Day's and Gutenberg's early impression produced in the US was similar: whereas Day was hired by the Geological Survey to organize a new laboratory because of his experience in high-temperature research, Gutenberg displayed his deep knowledge of observational geophysics to Caltech's colleagues and rector. Day headed CIW's Geophysical Laboratory from 1906 to 1936; and Gutenberg took charge of Caltech's Seismological Laboratory from 1946 to 1957. Their experience in European research centers was key for the establishment of geophysical laboratories in the U.S. several decades later.

The following abbreviations are used: CGS (U.S. Coast and Geodetic Survey); CIW (Carnegie Institution of Washington); GL (Geophysical Laboratory); RAS (Royal Astronomical Society).

\section{References}

Abelson, P.H. (1975). Arthur Louis Day, 1869-1960, Biographical Memoirs of the National Academy of Sciences, 47, 27-47.

Agnew, D.C. (2003). History of seismology, in International Handbook of Earthquake and Engineering Seismology, William Hung Kan Lee et al. (Editors), Academic Press, Amsterdam, Part A, 3-11.

Ahrens, T.J. (1996). Albert Francis Birch: August 22, 1903-January 30, 1992, Biographical Memoirs of the National Academy of Sciences, 37, 3-24.

Anderson, D.L. (1974). The Seismological Laboratory: Past and future, Engineering and Science, 38, 9-13.

Anduaga, A. (2009). Geofísica, economía y sociedad en la España contemporánea, Consejo Superior de Investigaciones Científicas, Fundación J. García-Siñeriz, Madrid.

Anduaga, A. (2016). Geophysics, Realism, and Industry. How Commercial Interests Shaped Geophysical Conceptions, 1900-1960, Oxford University Press, Oxford.

Barth, K.H. (2000). Detecting the Cold War: Seismology and Nuclear Weapons Testing, 1945-1970. PhD dissertation, University of Minnesota.

Birch, A.F. (1960). Reginald Aldworth Daly, May 19, 1871-September 19, 1957, Biographical Memoirs of the National Academy of Sciences, 34, 31-64.

Birch, A.F. (1979). Reminiscences and digressions, Annual Review of Earth and Planetary Sciences, 7, 1-9.

Bolt, B.A. (1979). Perry Byerly (1897-1978), Bulletin of the Seismological Society of America, 69, 928-945.

Bolt, B.A. (1985). The development of earthquake seismology in the Western United States, in Geologists and Ideas: A History of North American Geology, Ellen T. Drake and William M. Jordan (Editors), Geological Society of America, Boulder, Colorado, 471-480.

Bolt, B.A. (1989). One hundred years of contributions of the University of California Seismographic Stations, in Observatory Seismology, Joe J. Litehiser (Editor), University of California Press, Berkeley, 24-50.

Brinckmeier, G. (1955). Nachruf. Richard Ambronn, 1887-1954, Erdöl und Kohle, 8, 443.

Brush, S.G. (1980). Discovery of the Earth's core, American Journal of Physics, 48, 705-724.

Brush, S.G. and C.S. Gillmor (1995). Geophysics, in Twentieth Century Physics, Vol. 3, Laurie M. Brown, Abraham Pais, and A. Brian Pippard (Editors), Institute of Physics Publ., Bristol, 1943-2016. 


\section{Aitor Anduaga}

Brush, S.G. (1978). Planetary science: From underground to underdog, Scientia, 113, 771-787.

Bullard, E.C. (1980). William Maurice Ewing, May 12, 1906-May 4, 1974, Biographical Memoirs of the National Academy of Sciences, 51, 119-194.

Burchfield, J.D. (1975). Lord Kelvin and the Age of the Earth, SHP, New York.

Byerly, P. (1958). The beginnings of seismology in America, in Symposium on the Physical and Earth Sciences: Honoring the Twenty-fifth Presidential Year of Robert Gordon Sproul, University of California, Berkeley, 42-52.

Byerly, P. (1964). History of the Seismological Society of America, Bull. Seismol. Soc. Am., 54, 1723-1741.

Byerly, P. and W.V. Stauder (1958). James B. Macelwane, September 28, 1883-February 15, 1956, Biographical Memoirs of the National Academy of Sciences, 31, 254-281.

Cook, A. (1990). Sir Harold Jeffreys. 2 April 1891-18 March 1989, Biographical Memoirs of Fellows of the Royal Society, 36, 302-333.

Cremer, M. (2001). Seismik zu Beginn des 20. Jahrhunderts: Internationalität und Disziplinbildung, ERS-Verlag, Berlin.

Day, A. (1938). An adventure in scientific collaboration, in Cooperation in Research, Carnegie Institution of Washington, Washington, D.C., 3-35.

Dewey, J. and P. Byerly (1969). The early history of seismometry (to 1900), Bull. of the Seismol. Soc. Am., 59, $183-227$.

Doel, R.E. (1997). The earth sciences and geophysics, in Science in the Twentieth Century, John Krige and Dominique Pestre (Editors), Harwood Academic Publishers, Paris, 391-416.

Doel, R.E. (1998). Geophysics in universities, in Sciences of the Earth. An Encyclopedia of Events, People and Phenomena, Vol. 1, Gregory A. Good (Editor), Garland Publishing Inc., New York, 380-384.

Eckley, W. (2004). Rocky Mountains to the World: A History of the Colorado School of Mines. The Donning Company Publishers, Virginia Beach, VA.

Forbes, E.G. (1967). The life and work of Tobias Mayer (1723-62), Quarterly J. Royal Astron. Soc., 8, $227-251$.

Geschwind, C.H. (1998). Embracing science and research: Early twentieth-century Jesuits and seismology in the United States, Isis, 89, 27-49.

Geschwind, C.H. (2001). California Earthquakes: Science, Risk \& the Politics of Hazard Mitigation. The Johns Hopkins University Press, Baltimore.

Gibson, R.E. (1980). Leason Heberling Adams, January 16, 1887-August 20, 1969, Biographical Memoirs of the National Academy of Sciences, 52, 3-33.

Good, G.A. (1991). The Rockefeller Foundation, the Leipzig Geophysical Institute, and national socialism in the 1930s, Historical Studies in the Physical Sciences, 21, 299-316.

Good, G.A. (2000). The assembly of geophysics: Scientific disciplines as frameworks of consensus, Studies in History and Philosophy of Science, 31, 259- 292.

Good, G.A. (1985). Geomagnetics and scientific institutions in 19th century America, EOS: Transactions of the American Geophysical Union, 66, 521-526.

Goodstein, J.R. (1984). Waves in the Earth: Seismology comes to Southern California. Historical Studies in the Physical Sciences, 14, 201-230.

Goranson, R.W. (1928). Transmission of elastic waves through surface-rocks, Terrestrial Magnetism and Atmospheric Electricity Journal, 33, 143-148.

Green, C.H. (1979). John Clarence Karcher, 1894-1978. Father of the reflection seismograph, Geophys, 44, 1018-1021.

Gutenberg, B. and C.F. Richter (1934-1939). On seismic waves, Gerland’s Beiträge zur Geophysik, 43(1934), 56-133; 45(1935), 280-360; 47(1936), 73-131; 54(1939), 94-136.

Gutenberg, B. (1934). Das “Seismological Laboratory” in Pasadena, in Ergebnisse der Kosmischen Physik, Victor Conrad and Ludwig Weickmann (Editors), Akademische Verlagsgesellschaft, Leipzig, 213-237.

Heck, N.H. (1944). The Jesuit contribution to seismology in the U.S.A., Thought, 19, 221-228.

Heiland, C.A. and D. Wantland (1940). Organization of a department of geophysics, Transactions of the American Institute of Mining and Metallurgical Engineers, 138, 53-61.

Hemley, R.J. (2006). Erskine Williamson, extreme conditions, and the birth of mineral physics, Phys.Today, 59, 50-56.

Holden, E.S. (1898). A Catalogue of Earthquakes on the Pacific Coast, 1769-1897, Washington Smithsonian Institution, Washington, D.C.

Hollister, J.C. (1957). Carl A. Heiland, Geophys., 22, 157-158.

Hough, S.E. (2007). Richter's Scale: Measure of an Earthquake, Measure of a Man. Princeton University Press, 


\section{Crustal Seismology: traditions and styles}

Princeton, N.J.

Hubbert, M. K. (1940). The place of geophysics in a department of geology, Transactions of the American Institute of mining and Metallurgical Engineers, 138, 34-52.

Jeffreys, H. (1926). On near earthquakes, Monthly Notices of the Royal Astronomical Society, Geophysical Supplement, 1, 385-402.

Jeffreys, H. (1931). Scientific Inference. Cambridge University Press, Cambridge.

Jeffreys, H. (1936). Geophysics and the Royal Astronomical Society, Monthly Notices of the Royal Astronomical Society, 96, 384-387.

Jeffreys, H. and B.S. Jeffreys (Editors). (1971-1977). Collected Papers of Sir Harold Jeffreys on Geophysics and other Sciences. Gordon \& Breach, London.

Jeffreys, H. and D. Wrinch (1921). On certain fundamental principles of scientific inquiry, The Philosophical Magazine, 42, 369-390.

Karcher, J.C. (1987). The reflection seismograph: Its invention and use in the discovery of oil and gas fields, The Leading Edge, 6, 10-19.

Kemble, E.C. and F. Birch (1970). Percy Williams Bridgman, 1882-1961, Biographical Memoirs: National Academy of Sciences, 41, 23-67.

Keppner, G. (1993). Zünd-Stoff Erdöl. Ludger Mintrop, Pionier und Begründer der Angewandten Seismik, Kultur \& Teknik, 1, 38-45.

Kertz, W. (2002). Biographisches Lexikon zur Geschichte der Geophysik. Braunschweigische Wissenschaftliche Gessellschaft, Braunschweig.

Kertz, W. (1991). Ludger Mintrop, der die angewandte Geophysik zum Erfolg brachte, Mitteilungen der Deutschen Geophysikalischen Gesellschaft, 3, 2-16.

Keys, D.A. (1940). Teaching geophysics in a department of physics, Transactions of the American Institute of Mining and Metallurgical Engineers, 138, 62-66.

Knopoff, L. (1999). Beno Gutenberg, June 4, 1889-January 25, 1960, Biographical Memoirs of the National Academy of Sciences, 76, 115-148.

Knopoff, L. and C.P. Slichter (2004). Louis Byrne Slichter, 1896-1978, Biographical Memoirs of the National Academy of Sciences, 85, 3-22.

Kushner, D. (1993). Sir George Darwin and a British school of geophysics, Osiris, 8, 196-223.

Kushner, D. (1990). The Emergence of Geophysics in Nineteenth-Century Britain, PhD dissertation, Princeton University.

Lawson, A.C. (Editor). (1908-1910). The California Earthquake of April 18, 1906: Report of the State Earthquake Investigation Commission, Carnegie Institution of Washington, Washington, D.C., Facsimile ed. Vols. 1-2, 1969; atlas 1970.

Lawyer, L.C., C.C. Bates, and R.B. Rice (2001). Geophysics in the Affairs of Mankind: A Personalized History of Exploration Geophysics. $2^{\text {nd }}$ edition, Society of Exploration Geophysicists, Tulsa, Oklahoma.

Lehmann, K. (1965). Ludger Mintrop: der große Markscheider und Geophysiker; ein Lebensbild, Herne Kartenberg.

Leuschner, A.O. (1904). History and aims of the students' Observatory, Publications of the Astronomical Society of the Pacific, 16, 68-77.

Louderback, G.D. (1942). History of the University of California Seismographic Stations and related activities, Bulletin of the Seismological Society of America, 32, 205-229.

Macelwane, J.B. (1923). A study of the relation between the periods of elastic waves and the distances traveled by them, based on the seismographic records of the California earthquake January 31, 1922, Bulletin of the Seismological Society of America, 13, 13-69.

Macelwane, J.B. (1926). The Jesuit Seismographic Stations in the United States and Canada-A retrospect, Bull. Seismol. Soc. Am., 16, 187-193.

Mintrop, L. (1930). On The History of the Seismic Method for the Investigation of Underground Formations and Mineral Deposits. Seismos G.M.B.H., Hannover.

Mintrop, L. (1947). 100 Jahre physikalische Erdbebenforschung und Sprengseismik, Die Naturwissenschaften, 9-10, 258-262, 289-295.

Mohorovičić, A. (1910). Das Beben vom 8.x.1909, Jahrbuch des Meteorologischen Observatoriums in Zagreb (Agram) fur das Jahr 1909, 9 (4), 1-63. 


\section{Aitor Anduaga}

Mooney, W. D. (2007). Crust and Lithospheric Structure - Global Crustal Structure, in Seismology and the structure of the Earth. Treatise on Geophysics 1, B. Romanowicz and A. Dziewonski (Editors), Elsevier, Amsterdam, 361-417.

Mothes, H. (1927). Seismische Dickenmessungen von Gletschereis, Zeitschrift für Geophysik, 3, 121-134.

Neuenschwander, E. and H.W. Burmann (1994). Die Entwicklung der Mathematik an der Universität Göttingen, in Die Geschichte der Verfassung und der Fachbereiche der Georg-August-Universität zu Göttingen, HansGünther Schlotter (Editor), Vandenhoeck \& Rupprecht, Göttingen, 141-159.

Ochs, K.H. (1992). The rise of American mining engineers: A case study of the Colorado School of Mines, Technology and Culture, 33, 278-301.

Okamoto, T. (2004). Percy Williams Bridgman and the Evolution of Operationalism. PhD dissertation, University of Tokyo.

Oldham, R.D. (1906). The Constitution of the Interior of the Earth, as Revealed by Earthquakes, Quarterly J. Geol. Soc. London, 62, 456-473.

Olesko, K.M. (1991). Physics as a Calling: Discipline and Practice in the Königsberg Seminar for Physics, Cornell University Press, Ithaca, N.Y.

Owen, E.W. (1975). Trek of the Oil Finders: A History of Exploration for Petroleum, The A.A.P.G., Tulsa, Oklahoma.

Press, F. (1978). Victor Hugo Benioff, 1899-1968, Biographical Memoirs of the National Academy of Sciences (Washington, D.C.), 43, 27-40.

Pyenson, L. (1985). Cultural Imperialism and Exact Sciences: German Expansion Overseas, 1900-1930, Peter Lang, New York.

Richter, C.F. (1935) An Instrumental Earthquake Magnitude Scale, Bulletin of the Seismological Society of America, 25 (1), 1-32.

Richter, C.F. (1962). Memorial to Beno Gutenberg (1889-1960), Proceedings of the GSA, Annual Report for 1960, 93-104.

Schleusener, A. (1956). In Memoriam Prof. Dr. h.c. Ludger Mintrop, Zeitschrift für Geophysik, 22, 58-61.

Schweitzer, J. (2003). Early German contributions to modern seismology, in International Handbook of Earthquake and Engineering Seismology, William Hung Kan Lee et al. (Editors), Academic Press, Amsterdam, Part B, Ch. 79.24 .

Servos, J.W. (1984). To explore the borderland: The foundation of the Geophysical Laboratory of the Carnegie Institution of Washington, Historical Studies in the Physical and Biological Sciences, 14, 147-186.

Servos, J.W. (1986). Mathematics and the physical sciences in America, 1880-1930, Isis, 77, 611-629.

Smith, C. (1985). Geologists and mathematicians: The rise of physical geology, in Wranglers and Physicists: Studies on Cambridge Physics in the Nineteenth Century, Peter M. Harman (Editor), Manchester University Press, Manchester, 49-83.

Udías, A. (2000). Observatories of the Society of Jesus, 1814-1998, Archivum Historicum Societatis Jesu, 137, 151-178.

Udías, A. and W. Stauder (2002). The Jesuit Contribution to Seismology, in International Handbook of Earthquake and Engineering Seismology, W.H.K. Lee, H. Kanamori, P.C. Jennins, and C. Kisslinger (Editors), Academic Press, San Diego, CA., 19-27.

Van Tuyl, F.M. (1949). Geological engineering at the Colorado School of Mines, The Mines Magazine, 37-41.

Verhoogen, J. (1985). Perry Byerly, 1897-1978, Biographical Memoirs of the National Academy of Sciences (Washington, D.C.), 55, 95-105.

Westermann, A. (2011). Disciplining the Earth: Earthquake observation in Switzerland and Germany at the turn of the nineteenth century, Environment and History, 17, 53-77.

Wiechert, E. (1906). Das Institut für Geophysik der Universität Göttingen, in Die Physikalischen Institute der Universität Göttingen. Festschrift im Anschlusse an die Einweihung der Neubauten am 9. dezember 1905, Akademia Georgia Augusta (Editor), B. G. Teubner, Leipzig, 119-188.

Wood, H.O. (1916). The earthquake problem in the western United States, Bulletin of the Seismological Society of America, 6, 197-217.

Wood, H.O. (1918). The study of earthquakes in southern California, Bulletin of the Seismological Society of America, 8, 28-33.

Wood, H.O. (1921). On a piezo-electrical accelerograph, Bulletin of the Seismological Society of America, 11, 15-57.

Wood, H.O. (1929). Seismological conference at Pasadena, Bulletin of the Seismological Society of America, 19, 208-234. 
Yoder, H.S. (1994). Development and promotion of the initial scientific program for the Geophysical Laboratory, in The Earth, the Heavens and the Carnegie Institution of Washington, Gregory A. Good (Editor), The American Geophysical Union, Washington D.C., 21-28.

Yoder, H.S. (2004). Centennial History of the Carnegie Institution of Washington: The Geophysical Laboratory. Vol. III. Cambridge University Press, Cambridge. 